\title{
Hyperandrogenemia and high prolactin in congenital utero-vaginal aplasia patients
}

\author{
Patricia G Oppelt ${ }^{1}$, Andreas Müller , Liana Stephan, Ralf Dittrich¹, Johannes Lermann, \\ Christian Büttner ${ }^{2}$, Arif B Ekici², Gabi Conzelmann³, Harald Seeger ${ }^{3}$, Dorit Schöller ${ }^{3}$, \\ Katharina Rall ${ }^{3}$, Matthias W Beckmann¹, Pamela L Strissel ${ }^{1}$, Sara Y Brucker ${ }^{3}$ and Reiner Strick ${ }^{1}$ \\ ${ }^{1}$ Department of Gynecology and Obstetrics, Laboratory of Molecular Medicine, University Hospital Erlangen, \\ Erlangen, Germany, ${ }^{2}$ Institute of Human Genetics, University Hospital, Friedrich-Alexander-University of \\ Erlangen-Nürnberg, Erlangen, Germany and ${ }^{3}$ Department of Gynecology and Obstetrics, University Hospital \\ Tübingen, Tübingen, Germany
}

Correspondence should be addressed to R Strick; Email: Reiner.Strick@uk-erlangen.de

\begin{abstract}
Patients with the Mayer-Rokitansky-Küster-Hauser syndrome (MRKH) have a congenital utero-vaginal cervical aplasia, but normal or hypoplastic adnexa and develop with normal female phenotype. Some reports mostly demonstrated regular steroid hormone levels in small MRKH cohorts including single MRKH patients with hyperandrogenemia and a clinical presentationof hirsutism and acne has also been shown. Genetically a correlation of WNT4 mutations with singular MRKH patients and hyperandrogenemia was noted. This study analyzed the hormone status of 215 MRKH patients by determining the levels of luteinizing hormone (LH), follicle-stimulating hormone (FSH), estradiol, 17-OH progesterone, testosterone, dehydroepiandrosterone sulfate (DHEAS), sex hormone-binding globulin (SHBG) and prolactin to determine the incidence of hyperandrogenemia and hyperprolactinemia in MRKH patients. Additional calculations and a ratio of free androgen index and biologically active testosterone revealed a hyperandrogenemia rate of $\mathbf{4 8 . 3} \%$, hyperprolactinemia of $9.8 \%$ and combined hyperandrogenemia and hyperprolactinemia of $4.2 \%$ in MRKH patients. The rates of hirsutism, acne and especially polycystic ovary syndrome (PCOS) were in the normal range of the population and showed no correlation with hyperandrogenemia. A weekly hormone assessment over 30 days comparing 5 controls and 7 MRKH patients revealed high androgen and prolactin, but lower LH/FSH and SHBG levels with MRKH patients. The sequencing of WNT4, WNT5A, WNT7A and WNT9B demonstrated no significant mutations correlating with hyperandrogenemia. Taken together, this study shows that over $52 \%$ of MRKH patients have hyperandrogenemia without clinical presentation and $14 \%$ hyperprolactinemia, which appeals for general hormone assessment and adjustments of MRKH patients.

Reproduction (2017) 153 555-563
\end{abstract}

\section{Introduction}

Congenital utero-vaginal aplasia or Mayer-RokitanskyKüster-Hauser syndrome (MRKH) (OMIM 277000) is characterized by non-fused uterus rudiments, aplasia of the cervix and vagina, but normal or hypoplastic bilateral adnexa and clinically presenting with primary amenorrhea. MRKH patients have a normal development of the female phenotype and karyotype (46, XX) and an incidence of 1 in 4000 or 5000 newborn females (Cheroki et al. 2006). The MRKH syndrome is regarded as a developmental malformation of the Müllerian (paramesonephric) ducts, occurring in utero between the fourth and twelfth week of pregnancy, into oviducts, the uterus, cervix and upper vagina, whereas the Wolffian (mesonephric) ducts regress without fusing with the Müllerian ducts (Ludwig 1998). Additional data from the mouse show that the vaginal aplasia could be due to the failure of the genital ducts to descend beyond the neck of the bladder (Drews 2007). In addition to the MRKH syndrome phenotype (type I), additional malformations of other organs or tissues are known (type II). In 36 or $57.6 \%$ of MRKH cases, renal malformations including aplasia have been reported (Oppelt et al. 2006, Rall et al. 2015). Rarely MRKH patients have additional cervicothoracic somite anomalies, unilateral renal agenesis and conductive deafness, which are also known as MURCS association (OMIM 601076) (Duncan et al. 1979). To date, the molecular basis for the MRKH syndrome is unknown, although a few mutated candidate genes have been found, but they only have accounted for $<10 \%$ of the analyzed cases. Brown (1959) and Fraser and coworkers (Fraser et al. 1973) have shown that ovarian function is intact, as evident in correctly timed pubarche and thelarche and the presence of a biphasic basal temperature curve. 
However, abnormalities of the ovaries have been detected in $15 \%$ (Strübbe et al. 1993) and $5.7 \%$ of MRKH patients (Oppelt et al. 2006) and ectopic ovaries in $41 \%$ of MRKH patients (Hall-Craggs et al. 2013).

Steroid and pituitary hormonal levels have been demonstrated within normal limits determined from single cases or smaller cohorts of MRKH patients (Fraser et al. 1973, Ylikorkala \& Viinikka 1979, Egarter et al. 1988, Carranza-Lira et al. 1999). However, some of the latter studies also showed indications that hormonal dysregulation, like hyperprolactinemia, higher progesterone levels, differences in luteal phase estrogens and aberrant gonadotrophin function exists in some MRKH patients.

Hyperandrogenemia is one of the most common endocrinological abnormalities in women. Causes for hyperandrogenemia are rarely androgensecreting neoplasms or adrenal hyperplasias, but hyperandrogenemia is more common in women of reproductive age with polycystic ovaries (PCOS) affecting $5-10 \%$ of females (Fauser et al. 2012) showing menstrual irregularity, elevated androgens, hyperinsulinemia from insulin resistance and disturbed activation, survival and growth of follicles. Interestingly, a recent questionnaire survey of MRKH patients showed that $60.1 \%$ of these patients had hyperandrogenemia without clinical signs of virilization, where clinical acne was reported in $13 \%$ and PCOS in $5.8 \%$ of patients (Rall et al. 2014). Currently, the incidence of both hyperandrogenemia and hyperprolactinemia is not known in MRKH patients. In addition, a weekly hormone assessment of MRKH patients over one month has not been compared to control women or between MRKH patients. Considering genetic analyses of MRKH patients with hyperandrogenemia, a correlation with heterozygous WNT4 mutations like p.E226G, p.R83C, p.L12P and p.A233T were found (Biason-Lauber et al. 2004, 2007, Philibert et al. 2008, 2011).

WNT genes are essential for Müllerian duct development as shown with knockout and knockin mice experiments: Wnt4-mutant female mice lack Müllerian ducts but not the Wolffian ducts (Heikkilä et al. 2001) and inactivation of Wnt4 led to a premature ovarian failure (Prunskaite-Hyyryläinen et al. 2014). Wnt5a knockout mice exhibited dwarfism, truncated limbs, hypoplastic genitals and anorectal malformation (Yamaguchi et al. 1999, Tai et al. 2009). Wnt7a, which is expressed in the Müllerian duct epithelium, was demonstrated as a requirement for the differentiation of the oviduct and uterus (Parr \& McMahon 1998), knockout mice had abnormal oviduct and uterus development and limb developmental defects (Heikkilä et al. 2001). Wnt9b was shown to be essential for the caudal extension of the Müllerian ducts (Parr \& McMahon 1998), expressed in the metanephric and mesonephric tubules and caudal extension of the Müllerian duct. Wnt9b knockout mice were lethal post-partum with kidney malformations
(Carroll et al. 2005). Interestingly, WNT7A functional missense mutations are associated with the Al-AwadiRaas-Rothschild syndrome (AARRS) (OMIM 276820) and the less severe Fuhrmann syndrome (OMIM 228930), defined by loss of lower limbs, digits of the hands as well as urogenital abnormalities (Al-Qattan et al. 2013).

By contrast to earlier hormone evaluations, the present study analyzed $215 \mathrm{MRKH}$ patients for $\mathrm{LH}, \mathrm{FSH}$, estradiol (E2), 17-OH-progesterone, prolactin, DHEAS, $\mathrm{TT}, \mathrm{FT}, \mathrm{FAI}, \mathrm{cBT}$ and $\mathrm{SHBG}$, as well as clinical signs of PCOS, acne and hirsutism. One main objective was to determine the incidence of hyperandrogenemia and hyperprolactinemia in our MRKH cohort. Another aim of this study was to follow hormone levels of MRKH patients with and without hyperandrogenemia over 30 days to determine the differences compared to each other and normal control women. In addition, a subset of these MRKH patients was sequenced for WNT4, WNT5A, WNT7A and WNT9B genes to correlate hyperandrogenemia in MRKH with WNT mutations.

\section{Materials and methods}

\section{MRKH patients}

All patient handling and patient blood samples were in accordance with the Ethics Committee review and approval at the University of Erlangen-Nuremberg (\#256_14). All patients gave written informed consent prior to blood donation. The $215 \mathrm{MRKH}$ patients (mean age $30.42 \pm 8.6$ years S.D.) were either from the Department of Gynecology and Obstetrics at the University Hospital of Erlangen or from the University of Tübingen, Department of Gynecology and Obstetrics, in Germany (Table 1). The 215 patients were grouped according to the VCUAM classification using laparoscopy, laparotomy, hysteroscopy, sonography, urogram and/or magnetic resonance imaging (Oppelt et al. 2005).

\section{Hormone analyses and criteria for assembly of hormone groups}

All patient serum samples were collected at the time of initial diagnosis or at regular gynecological examinations. Measurements were performed in a routine diagnostic endocrinology laboratory using established commercial assays (IMMULITE 2000, Siemens Medical Solutions Diagnostics), routinely monitored by participation in external quality-control programs. Total testosterone (TT), dehydroepiandrosterone sulfate (DHEAS), sex hormonebinding globulin (SHBG), luteinizing hormone (LH), folliclestimulating hormone (FSH), estradiol (E2) and prolactin (PRL) were measured with chemiluminescent enzyme immunoassays (IMMULITE 2000, Siemens Medical Solutions Diagnostics), as described in detail previously (Mueller et al. 2006a,b, 2007). 17-OHP was measured with a specific enzyme immunoassay (17-OH-Progesterone ELISA, IBL International $\mathrm{GmbH}$, Hamburg, Germany). The results of the hormone analyses were used to divide the MRKH patients 
Table 1 Clinical characteristics of the analyzed MRKH patients.

\begin{tabular}{lcccc}
\hline & \multicolumn{4}{c}{ MRKH patients with } \\
\cline { 2 - 5 } & Normal hormones & Hyperandrogenemia & Hyperprolactinemia & Hyperprolactinemia + Hyperandrogenemia \\
\hline$n(\%)$ & $81(37.6 \%)$ & $104(48.4 \%)$ & $21(9.8 \%)$ & $9(4.2 \%)$ \\
Age (years) & $31.84( \pm 1.14)$ & $28.47( \pm 0.68)$ & $34.67( \pm 1.82)$ & $30.33( \pm 1.77)$ \\
BMl & $21.5( \pm 0.37)$ & $22.73( \pm 0.51)$ & $21.99( \pm 0.74)$ & $25.01( \pm 1.51)$ \\
Amenorrhea & $81(100 \%)$ & $104(100 \%)$ & $21(100 \%)$ & $9(100 \%)$ \\
Acne & $3(3.7 \%$ or $1.4 \%$ of total $)$ & $0(0 \%)$ & $1(4.8 \%$ or $0.5 \%$ of total $)$ & $1(11.1 \%$ or $0.5 \%$ of total $)$ \\
Hirsutism & $0(0 \%)$ & $0(0 \%)$ & $1(4.8 \%$ or $0.5 \%$ of total $)$ & $1(11.1 \%$ or $0.5 \%$ of total $)$ \\
PCO & $4(4.9 \%$ or $1.9 \%$ of total $)$ & $10(9.6 \%$ or $4.6 \%$ of total $)$ & $0(0 \%)$ & $1(11.1 \%$ or $0.5 \%$ of total $)$ \\
Smoker & $7(8.6 \%$ or $3.2 \%$ of total $)$ & $1(1.0 \%$ or $0.5 \%$ of total $)$ & $1(4.8 \%$ or $0.5 \%$ of total $)$ & $1(11.1 \%$ or $0.5 \%$ of total $)$ \\
\hline
\end{tabular}

Of the total MRKH patients $(n=215), 5(2.3 \%)$ patients had clinical acne, $2(0.9 \%)$ hirsutism, $15(7 \%)$ PCO and $10(4.6 \%)$ patients were smokers.

into four groups: (1) MRKH with normal hormone values; (2) MRKH with hyperandrogenemia but normal prolactin serum levels: elevated TT $(>2.0 \mathrm{nmol} / \mathrm{L})$, cFT $(>0.03 \mathrm{nmol} / \mathrm{L})$ or cBT $(>0.71 \mathrm{nmol} / \mathrm{L})$ according to Mueller and coworkers (Mueller et al. 2006a,b); (3) MRKH with hyperprolactinemia but normal androgen serum levels: elevated PRL over 530 IU/L according to Melmed and coworkers (Melmed et al. 2011) and (4) MRKH with hyperandrogenemia and hyperprolactinemia.

\section{0-day hormone assessment}

Five control patients with regular monthly cycle and seven MRKH patients, also included in the overall hormone study, were selected for donating serum every week over 5 weeks. Of the seven MRKH patients, four patients were classified as having normal hormone values and three with hyperandrogenemia. In addition, these seven MRKH patients did not present with PCOS, clinical acne or hirsutism. The control patients had a mean BMI of $21.61 \pm 0.69$ and mean age of $29.6 \pm 1.36$ years, the MRKH patients had a mean BMI of $19.28 \pm 1.08$ and a mean age of $21.85 \pm 0.8$ years.

\section{Genomic DNA extraction}

DNA from $8 \mathrm{~mL}$ blood collected in CPDA tubes (with citrate, phosphate, dextrose and adenine) was extracted as previously described (Ekici et al. 2013).

\section{PCR reactions and sequencing}

For a subset of the MRKH patients $(n=28)$, individual coding exons, splice sites as well as part of the $5^{\prime}$ and $3^{\prime}$ UTRs of the WNT4, WNT5A, WNT7A and WNT9B genes were amplified using specific primers (Supplementary Table 1, see section on supplementary data given at the end of this article) by polymerase chain reaction (PCR) with appropriate amplification protocols. Primer sequences were selected using Primer3 software to achieve amplicons of approximately $600 \mathrm{bp}$ regardless of the actual exon sizes. Larger exons were subdivided in different overlapping amplicons (Supplementary Table 1). PCR was performed with 50 ng genomic DNA, 10 pmol of each primer, $1 \cup$ Taq-polymerase and components (Invitrogen). PCR fragment purification and sequencing (BigDye Terminator v3.1 Cycle Sequencing Kit; Applied Biosystems) was done using an automated capillary sequencer (ABI Prism 3730 Genetic Analyzer; Applied Biosystems) according to Ekici et al. (2013). Nucleotide changes of both DNA strands were identified by alignment of generated sequences with the reference sequence (hg19/GRCh37/NCBI Build 37.1) using SeqManPro/LasergeneV.8 (DNASTAR, Madison, WI, USA).

\section{Statistical analysis}

The nonparametric Mann-Whitney test for independent samples was performed using IBM SPSS Statistics 21 (SPSS). For all tests, a $P<0.05$ was considered as statistically significant. For each mean value, a standard error of the mean (S.E.M.) was calculated.

\section{Results}

All 215 MRKH patients had primary amenorrhea with complete vaginal atresia (V5b), bilateral cervical aplasia (C2b) and bilateral rudimentary or aplastic uterus (U4b) according to the VCUAM classification (Oppelt et al. 2005). Seventy-two (33\%) of the 215 MRKH patients had additional kidney malformations (MR; malformation renal, mostly unilateral kidney agenesis), 42 (19.5\%) had skeletal malformations (MS, mostly scoliosis), 7 (3.2\%) cardiac defects (MC) and 4 $(1.9 \%)$ neurological aberrations $(\mathrm{MN})$. Twenty patients $(9.3 \%)$ had compound malformations of kidney and skeleton (MRS) and 5 patients (2.3\%) had multifactorial kidney, skeleton, cardiac and neurological defects (MRSC or MRSN) according to the VCUAM classification (Oppelt et al. 2005).

Of the $215 \mathrm{MRKH}$ patients, 5 patients $(2.3 \%)$ had clinical acne, 2 (0.9\%) hirsutism, 15 (7\%) PCOS and $10(4.6 \%)$ were smokers (Table 1). The $\mathrm{BMI}$ values between MRKH patients with normal hormone status $(21.51 \pm 0.37)$ and MRKH patients with hyperprolactinemia and hyperandrogenemia $(25.01 \pm 1.51)$ were significantly different $(P=0.02)$; and between the MRKH group with hyperprolactinemia $(21.99 \pm 0.74)$ and MRKH with hyperandrogenemia and hyperprolactinemia $(P=0.034)$. The total mean BMI of all 
215 MRKH patients was $22.29 \pm 0.31$, and the mean age of all MRKH patients was $30.44 \pm 0.59$ years (Table 1 ).

\section{Hormone analysis}

The hormone analysis of the 215 MRKH patients resulted into the subdivision of 4 cohorts: MRKH with normal hormone values (normal hormone) $(n=81$ or
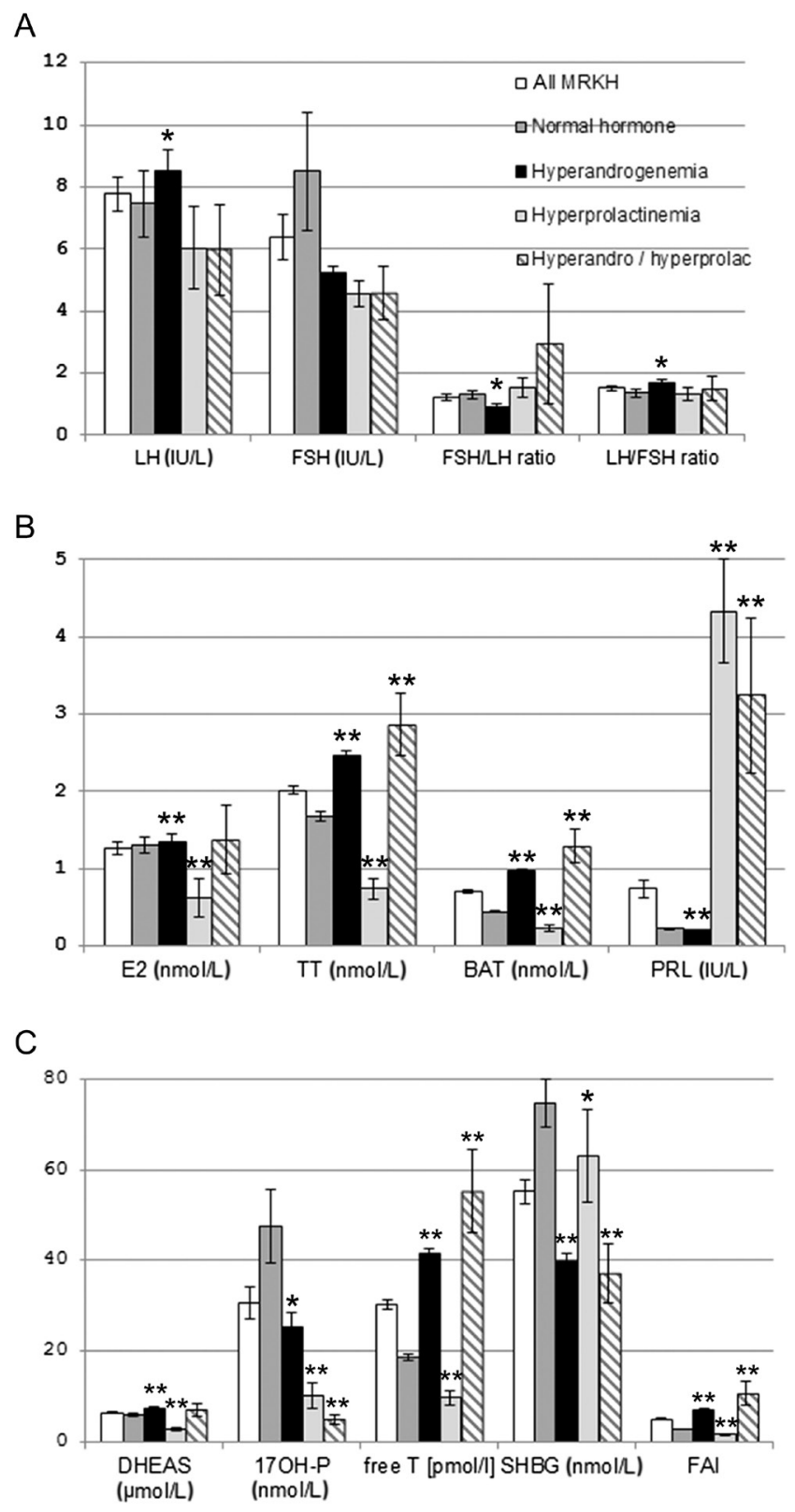

Figure 1 Hormone analysis of all MRKH patients $(n=215)$. Normal $=$ MRKH with normal hormone status; hyperandro $=M R K H$ with hyperandrogenemia; hyperprolac $=\mathrm{MRKH}$ with

hyperprolactinemia, hyperandro/hyperprolac $=\mathrm{MRKH}$ with hyperandrogenemia and hyperprolactinemia. Statistical correlations were performed against the group of MRKH with normal hormone status: ${ }^{*} P<0.05 ;{ }^{*} P<0.01$.
$37.7 \%)$, with hyperandrogenemia $(n=104$ or $48.3 \%)$, with hyperprolactinemia $(n=21$ or $9.8 \%)$ and both hyperandrogenemia and hyperprolactinemia $(n=9$ or $4.2 \%$ ) (Fig. 1). According to the single hormone values, FSH was not significantly different between the 4 cohorts, whereas LH was significantly increased by $14.2 \%$ in the hyperandrogenemia group $(P=0.00031)$. However, the $\mathrm{LH} / \mathrm{FSH}$ or $\mathrm{FSH} / \mathrm{LH}$ ratios were not different. Estradiol (E2) was significantly downregulated by $52.6 \%$ in the hyperprolactinemia group $(P=5.64 \mathrm{E}-06)$ compared to that in the MRKH normal hormone group, whereas the hyperandrogenemia and hyperandrogenemia/ hyperprolactinemia groups had similar E2 values. Hyperandrogenemia MRKH presented with highly significantly increased TT $(P=3.59 \mathrm{E}-15)$, cFT $(P=2.03 \mathrm{E}-$ 31), FAI $(P=2.67 \mathrm{E}-29), \mathrm{CBT}(P=8.18 \mathrm{E}-31)$ and DHEAS $(P=0.000053)$ levels compared to the MRKH normal hormone group. Except for DHEAS, highly significant increased levels of TT, FT, FAI and CBT were also detected in the hyperandrogenemia/hyperprolactinemia group. The hyperprolactinemia group showed highly significant decreases of TT, FT, FAI, CBT and DHEAS compared to those in the MRKH normal hormone group. The 17-OHP values were significantly downregulated for the hyperprolactinemia and hyperandrogenemia/ hyperprolactinemia groups compared to those in the MRKH normal hormone group. The SHBG was significantly lower in hyperandrogenemia, hyperprolactinemia and hyperandrogenemia/ hyperprolactinemia groups compared to those in MRKH normal hormone group. Compared to the MRKH normal hormone group, the hyperprolactinemia group showed a 19.7-fold $(P=1.91 \mathrm{E}-12)$ and 14.8-fold induction of $\mathrm{PRL}$ in the hyperandrogenemia/hyperprolactinemia group ( $P=9.38 \mathrm{E}-07)$ (Fig. 1). The association of the four different $M R K H$ patient hormone groups with the different adnexa (A) or additional malformations (M) did not show any significant correlation (Table 2).

\section{Month-long hormone assessment}

The analysis of $\mathrm{LH}, \mathrm{FSH}, \mathrm{E} 2,17-\mathrm{OHP}, \mathrm{TT}, \mathrm{cFT}, \mathrm{cBT}$, DHEAS, PRL and SHBG for 30 days (5 time points at $2-5,8-14,14-18,18-24$ and $24-30$ days) with $7 \mathrm{MRKH}$ and 5 control patients showed strong aberrations (Fig. 2). The mean values of the $7 \mathrm{MRKH}$ patients did not show a typical mid-monthly peak of $\mathrm{LH}$ and FSH. The values for E2, TT, cFT, CBT and DHEAS were continuously higher than those in the 5 control women. 17-OHP was similar between the MRKH and control women, with a strong increase at the luteal phase (after day 18). SHBG of the MRKH showed lower values at the end of the month (luteal phase), whereas PRL was higher at the beginning of the month (follicular phase) compared to that in the controls (Fig. 2). An additional month-long hormone comparison between the MRKH patients with hyperandrogenemia $(n=3)$ 
Table 2 Adnex (A) and additional malformations (M) correlating with total patient numbers and hormonal cohort.

\begin{tabular}{|c|c|c|c|c|}
\hline \multirow[b]{2}{*}{ Malformations } & \multicolumn{4}{|c|}{ MRKH patients with } \\
\hline & $\begin{array}{c}\text { Normal } \\
\text { hormones } \\
(n=81)\end{array}$ & $\begin{array}{c}\text { Hyper- } \\
\text { androgenemia } \\
(n=104)\end{array}$ & $\begin{array}{c}\text { Hyper- } \\
\text { prolactinemia } \\
(n=21)\end{array}$ & $\begin{array}{c}\text { Hyper- } \\
\text { androgenemia + } \\
\text { hyper- } \\
\text { prolactinemia } \\
(n=9)\end{array}$ \\
\hline \multicolumn{5}{|l|}{ Adnex } \\
\hline $\mathrm{A} \#$ & 4 & 6 & 3 & 1 \\
\hline $\mathrm{A} 0$ & 68 & 89 & 18 & 8 \\
\hline A1a & 1 & 0 & 0 & 0 \\
\hline $\mathrm{A} 1 \mathrm{~b}$ & 3 & 1 & 0 & 0 \\
\hline A2a & 2 & 6 & 0 & 0 \\
\hline $\mathrm{A} 2 \mathrm{~b}$ & 0 & 1 & 0 & 0 \\
\hline A3a & 3 & 1 & 0 & 0 \\
\hline \multicolumn{5}{|l|}{ Additional } \\
\hline $\mathrm{M} \#$ & 3 & 6 & 5 & 1 \\
\hline MO & 42 & 53 & 9 & 3 \\
\hline MR & 16 & 27 & 3 & 3 \\
\hline MRC & 0 & 1 & 0 & 0 \\
\hline MRS & 8 & 8 & 1 & 0 \\
\hline MRSC & 1 & 2 & 1 & 0 \\
\hline MRSN & 1 & 0 & 0 & 0 \\
\hline MS & 8 & 7 & 1 & 0 \\
\hline MSC & 1 & 0 & 0 & 0 \\
\hline MSN & 1 & 0 & 1 & 1 \\
\hline MC & 0 & 0 & 0 & 1 \\
\hline
\end{tabular}

A\#: unknown; A0: normal; A1a: unilateral tubal malformation, ovaries normal; A1b: bilateral tubal malformation, ovaries normal; A2a: unilateral hypoplasia/gonadal streak; A2b: bilateral hypoplasia/ gonadal streak; A3a: unilateral aplasia; C, cardiac; N, neurological; $\mathrm{R}$, renal; S, skeletal according to Oppelt et al. (2005).

and without hyperandrogenemia $(n=4)$ showed generally higher values of most analyzed hormones. Besides the finding of weekly significant higher values for TT and $\mathrm{CBT}$ of the MRKH patients with hyperandrogenemia, higher E2 and DHEAS were also detected (Fig. 3). Interestingly, the MRKH patients without hyperandrogenemia showed a relatively flat 17-OHP curve even after day 18 in contrast to the MRKH patients with hyperandrogenemia and to the control patients (Figs 2 and 3).

\section{WNT4, WNT5A, WNT7A, WNT9B sequencing}

A representative subset of the MRKH patients $(n=28)$ were also analyzed for WNT4, WNT5A, WNT7A and WNT9B exonic, intron-exon boundaries and UTR DNA changes (Fig. 4). This subset included $12 \mathrm{MRKH}$ patients with normal hormone status, 11 patients with hyperandrogenemia, 4 patients with hyperprolactinemia and 1 patient with combined hyperandrogenemia and hyperprolactinemia. As shown in Fig. 3, no novel mutation in WNT4, WNT5A, WNT7A and WNT9B was found, whereas known SNPs were detected. Interestingly, no SNPs were detected in WNT4, even with the 11 hyperandrogenemia patients. The only mutation with an amino acid exchange was found in WNT9B (rs4968281; p.M106T) present in all analyzed MRKH patients; however, this SNP is also found with a high probability in normal populations $(\mathrm{C} / \mathrm{C}=48.2 \%$, $\mathrm{C} / \mathrm{T} 41.1 \%, \mathrm{~T} / \mathrm{T}=10.7 \%)$. WNT5A, WNT7A and WNT9B mutations were equally distributed of the different hormone groups, without any significant difference (Fig. 4).

\section{Discussion}

Published serum analysis for DHEAS, TT, FAI, SHBG, $\mathrm{LH}$ and $\mathrm{LH} / \mathrm{FSH}$ ratio of normal female controls $(n=43$, mean age 32.4 years) and of PCOS patients $(n=86$, mean age 30 years) (O'Reilly et al. 2014) showed a similarity between MRKH with normal hormone levels and MRKH with hyperandrogenemia presented here. This correlation would imply a tendency of $\mathrm{MRKH}$ with hyperandrogenemia toward PCOS. However, the presented group of MRKH patients with normal hormone values in this study $(n=81)$ included 4 patients with PCOS (4.9\%) and the MRKH cohort with hyperandrogenemia $(n=104)$ involved 10 patients with PCOS $(9.6 \%)$ (Table 1$)$. Due to estimations, the prevalence of PCOS is set to $5-10 \%$ of women at the
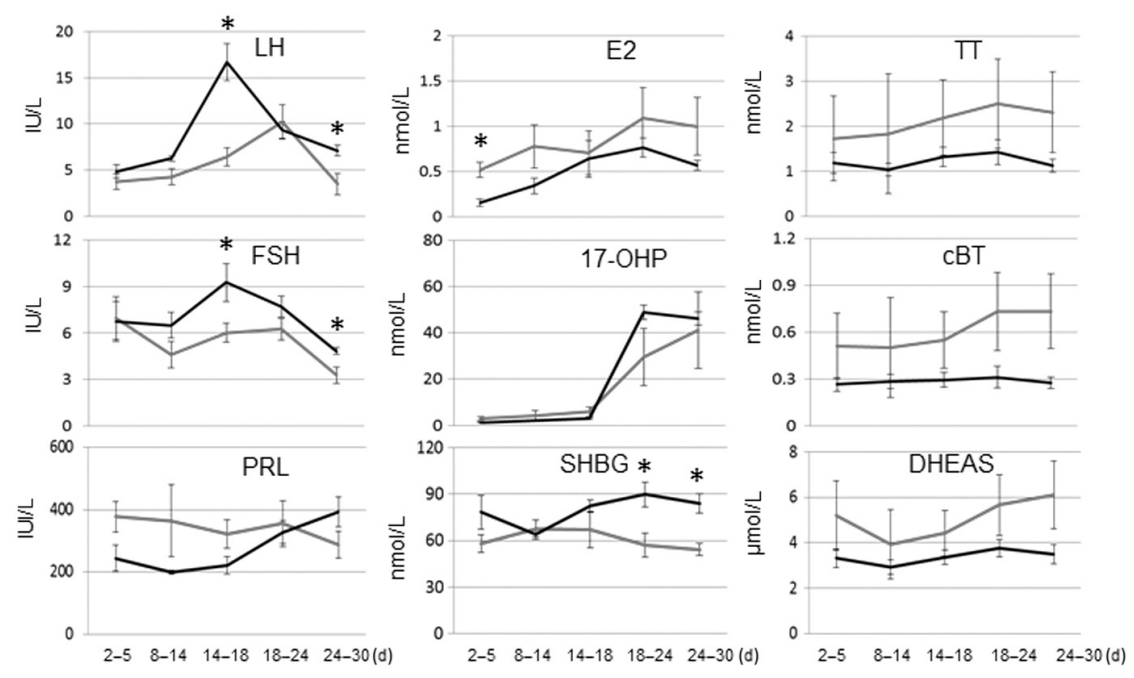

Figure 2 Hormone evaluations of $7 \mathrm{MRKH}$ patients (gray) including MRKH with normal hormones $(n=4)$ and MRKH with hyperandrogenemia $(n=3)$ and 5 normal women (black) with five consecutive serum analyses over thirty days (d). *Statistically significant $(P<0.05)$. 

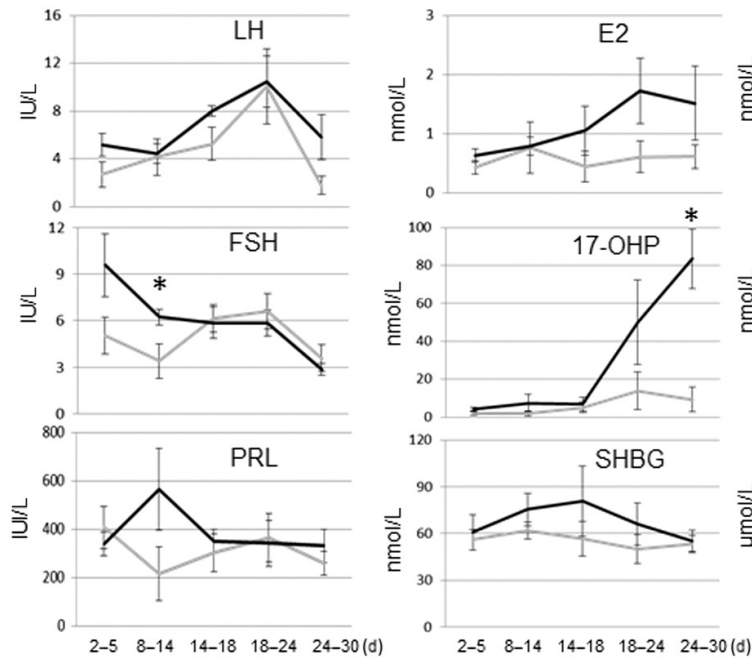
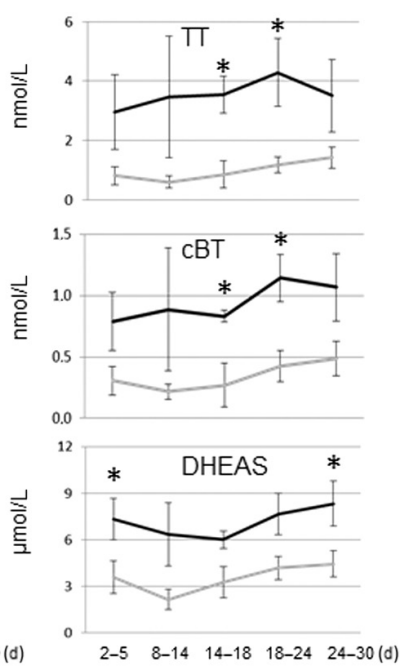

Figure 3 Hormone evaluations of the $7 \mathrm{MRKH}$ patients divided into a group with normal hormone values (gray) $(n=4)$ and MRKH with hyperandrogenemia (black) $(n=3)$.

*Statistically significant $(P<0.05)$. reproductive age (Fauser et al. 2012), which lies in the range of the single MRKH groups analyzed in this project. A recent questionnaire study, which also partly included MRKH patients used in the present study, showed that $61 \%$ (42 of 69 ) had hyperandrogenemia with $11.6 \%$ reporting physiological acne and 5.8\% PCOS (Rall et al. 2014). Therefore, we conclude that PCOS cannot be responsible for the hyperandrogenemia of MRKH patients, which represented for $48.3 \%$ of the total MRKH patients. Besides PCOS, adrenal hyperplasia or tumors of the adrenal glands or ovary or menopause can be the cause for hyperandrogenemia; however, these were not applicable to our MRKH cohort. In addition, a comparison of the ovaries and adnexes of

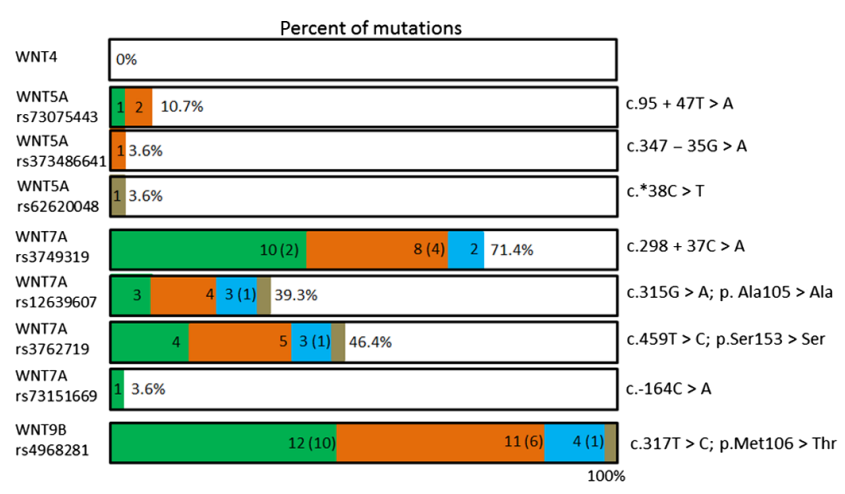

Figure 4 Sequencing analysis of MRKH patients $(n=28)$ for WNT4, WNT5A, WNT7A and WNT9B. The horizontal squares represent the amount and percent ( $n=28$ equaling $100 \%$ ) of specific SNPs, including the 'reference SNP' (rs) ID numbers on the left side. The color code represents green for MRKH with normal hormone status $(n=12)$, orange for MRKH with hyperandrogenemia $(n=11)$, blue for MRKH with hyperprolactinemia $(n=4)$ and olive for MRKH with hyperandrogenemia and hyperprolactinemia $(n=1)$. The numbers in parenthesis represent the total of homozygote mutations, without parenthesis the total of heterozygote mutations. On the right side are the coding (c) and protein (p) exchanges indicated. *The nucleotide $3^{\prime}$ of the translation stop codon (3'UTR). the MRKH with and without hyperandrogenemia did not show significant differences of malformation or aplasia (Table 2). The presented results of $48.3 \%$ MRKH patients with hyperandrogenemia and $37.7 \% \mathrm{MRKH}$ with normal hormone values cannot be easily explained. It is known that a steroid hormone exchange between the ovaries and uterus contributes to key regulatory mechanisms, especially during the menstrual cycle (Cicinelli et al. 2004). The missing essential hormone crosstalk and regulation between ovary and uterus in MRKH patients, which we previously proposed (Strissel et al. 2009) would apply to all MRKH patients, including those MRKH patients with hyperandrogenemia and a more deregulated hormone status, which was evident with the $\mathrm{LH} / \mathrm{FSH}$ and $\mathrm{FSH} / \mathrm{LH}$ ratio (Fig. 1).

Except for the MRKH group with hyperprolactinemia the E2 levels were similar between the different MRKH groups. Due to the conversion of TT to E2 via aromatase (CYP19A1), an overabundance of TT could be responsible for higher E2 levels. On the other hand, $P R L$ regulates $E 2$ and vice versa, which was seen in the hyperprolactinemia group, but not in the combined MRKH hyperandrogenemia/hyperprolactinemia group. Both MRKH groups with hyperandrogenemia and hyperprolactinemia had significantly low 17-OHP levels compared to those in the MRKH group with normal hormones. Compared to the MRKH group with normal hormone levels, the MRKH group with hyperprolactinemia had significantly low TT, FT, cBT, FAI and DHEAS, which was also found in normal women with high PRL levels (Wathen et al. 1985).

A previous analysis of $56 \mathrm{MRKH}$ patients and 22 female controls showed higher but insignificant levels of $\mathrm{LH}, \mathrm{FSH}, \mathrm{E} 2$, progesterone and activin $\mathrm{A}$ and lower levels of FSH and AMH in MRKH (Strissel et al. 2009). However, LH/FSH ratio levels were significantly higher in these MRKH patients, whereas inhibin B was undetectable in $41.1 \%$ of the MRKH patients (Strissel et al. 2009). These results and the results 
in the present study demonstrate that many $\mathrm{MRKH}$ patients have hormone phase irregularities with longer follicular or luteal phases as well as probably low oocyte numbers due to high activin A/inhibin B ratios. However, as shown by Ben-Rafael and coworkers (BenRafael et al. 1998) and recently by Raziel and coworkers (Raziel et al. 2012), which described the successful IVF and surrogacies from $14 \mathrm{MRKH}$ patients, genetic maternal ships of MRKH is possible. In addition, many MRKH patients also apply for uterus transplant projects (Erman Akar et al. 2015). Furthermore, one could predict that MRKH patients after successful uterine transplants could restore hormone irregularities caused by rescuing the ovarian uterine crosstalk.

The WNT4, WNT5A, WNT7A and WNT9B sequencing of $28 \mathrm{MRKH}$ patients yielded no significantly different mutations between the MRKH patients with normal hormone status and MRKH with hyperandrogenemia. Since the finding of WNT4 codogenic mutations of a few MRKH patients with hyperandrogenemia and clinical signs of hyperandrogenism, many WNT gene analyses were previously performed. However, despite the considerable correlation of WNT4 codogenic mutations in MRKH patients with hyperandrogenism (4 of 6 published MRKH patients with hyperandrogenism had WNT4 mutations) (Fontana et al. 2016), our negative sequencing results of $28 \mathrm{MRKH}$ patients, including 11 with hyperandrogenemia for WNT4 mutations confirm previous results, where $12 \mathrm{MRKH}$ patients with hyperandrogenism also presented with no WNT4 mutations (Gervasini et al. 2010). Several studies analyzed for WNT4, WNT5A, WNT7A and WNT9B gene mutations in MRKH patients, but did not find these genes primarily contributing to the MRKH syndrome (Timmreck et al. 2003, ClementZiza et al. 2005, Cheroki et al. 2006, Ravel et al. 2009). However, some recent studies detected WNT9B mutations in a few MRKH patients (Tang et al. 2014, Wang et al. 2014, Waschk et al. 2016). Due to the close connection of hyperandrogenemia and PCOS, it was interesting to note that analyses of the WNT4 gene resulted in no correlating mutations (Canto et al. 2006), although genes regulating WNT signaling were found differentially expressed in PCOS patients compared to those in controls (Chazenbalk et al. 2012). It is therefore reasonable that the WNT family members do not contribute to the MRKH etiology, however, could contribute to hyperandrogenemia in MRKH patients, but more on deregulated expression levels than due to inactivating mutations.

In summary, MRKH patients show deregulation of androgen hormones. Importantly, $48.3 \%$ presented with hyperandrogenemia, $9.8 \%$ with hyperprolactinemia and $4.2 \%$ of MRKH patients with both hyperandrogenemia and hyperprolactinemia. All these MRKH patients did not have significant mutations of the WNT4, WNT5A, WNT7A and WNT9B genes. Weekly hormone analyses over one month showed higher E2, TT, cBT and DHEAS in MRKH patients compared to those in control patients, which were also higher in MRKH patients with hyperandrogenemia compared to MRKH patients without hyperandrogenemia. We conclude that one recommendation could be to implement a more detailed hormone evaluation of MRKH patients, and if necessary, perform a corrective intervention for deregulated hormones.

\section{Supplementary data}

This is linked to the online version of the paper at http://dx.doi. org/10.1530/REP-16-0408.

\section{Declaration of interest}

The authors declare that there is no conflict of interest that could be perceived as prejudicing the impartiality of the research reported.

\section{Funding}

This investigation was supported by a grant of the Else KrönerFresenius-Stiftung (2014_A276) to R S and A E.

\section{Acknowledgements}

The authors are especially grateful to the patients who participated in this study and to the Department of OB/GYN, Erlangen. P G Oppelt and A Müller: shared first authorship. SY Brucker and R Strick: shared senior author.

\section{References}

Al-Qattan MM, Shamseldin HE \& Alkuraya FS 2013 The WNT7A G204S mutation is associated with both Al-Awadi-Raas Rothschild syndrome and Fuhrmann syndrome phenotypes. Gene 516 168-170. (doi:10.1016/j.gene.2012.12.020)

Ben-Rafael Z, Bar-Hava I, Levy T \& Orvieto R 1998 Simplifying ovulation induction for surrogacy in women with Mayer-Rokitansky-KusterHauser syndrome. Human Reproduction 13 1470-1471. (doi:10.1093/ humrep/13.6.1470)

Biason-Lauber A, Konrad D, Navratil F \& Schoenle EJ 2004 A WNT4 mutation associated with Müllerian-duct regression and virilization in a 46,XX woman. New England Journal of Medicine 351 792-798. (doi:10.1056/NEJMoa040533)

Biason-Lauber A, De Filippo G, Konrad D, Scarano G, Nazzaro A \& Schoenle EJ 2007 WNT4 deficiency - a clinical phenotype distinct from the classic Mayer-Rokitansky-Kuster-Hauser syndrome: a case report. Human Reproduction 22 224-229. (doi:10.1093/humrep/del360)

Brown JB 1959 Preliminary observation on urinary oestrogen excretion in certain gynaecological disorders. Journal of Obstetrics and Gynaecology of the British Commonwealth 66 177-211. (doi:10.1111/j.1471-0528.1959.tb01999.x)

Canto P, Söderlund D, Carranza-Lira S \& Méndez JP 2006 Mutation analysis of the WNT-4 gene in patients with polycystic ovary syndrome. Gynecological Endocrinology $22 \quad 484-487$. (doi:10.1080/09513590600911698)

Carranza-Lira S, Forbii K \& Martinez-Chequer JC 1999 Rokitansky syndrome and MURCS association - clinical features and basis for 
diagnosis. International Journal of Fertility and Women's Medicine 44 250-255.

Carroll TJ, Park JS, Hayashi S, Majumdar A \& McMahon AP 2005 Wnt9b plays a central role in the regulation of mesenchymal to epithelial transitions underlying organogenesis of the mammalian urogenital system. Developmental Cell 9 283-292. (doi:10.1016/j. devcel.2005.05.016)

Chazenbalk G, Chen YH, Heneidi S, Lee JM, Pall M, Chen YD \& Azziz R 2012 Abnormal expression of genes involved in inflammation, lipid metabolism, and Wnt signaling in the adipose tissue of polycystic ovary syndrome. Journal of Clinical Endocrinology and Metabolism 97 E765E770. (doi:10.1210/jc.2011-2377)

Cheroki C, Krepischi-Santos AC, Rosenberg C, Jehee FS, MingroniNetto RC, Pavanello Filho I, Zanforlin Filho S, Kim CA, Bagnoli VR, Mendonça BB et al. 2006 Report of a del22q11 in a patient with MayerRokitansky-Küster-Hauser (MRKH) anomaly and exclusion of WNT4, RAR-gamma, and RXR-alpha as major genes determining MRKH anomaly in a study of 25 affected women. American Journal of Medical Genetics 140 1339-1342. (doi:10.1002/ajmg.a.31254)

Cicinelli E, Einer-Jensen N, Cignarelli M, Mangiacotti L, Luisi D \& Schonauer S 2004 Preferential transfer of endogenous ovarian steroid hormones to the uterus during both the follicular and luteal phases. Human Reproduction 19 2001-2004. (doi:10.1093/humrep/deh404)

Clément-Ziza M, Khen N, Gonzales J, Crétolle-Vastel C, Picard JY, TullioPelet A, Besmond C, Munnich A, Lyonnet S \& Nihoul-Fékété C 2005 Exclusion of WNT4 as a major gene in Rokitansky-Küster-Hauser anomaly. American Journal of Medical Genetics A 137 98-99. (doi:10.1093/ humrep/dei381)

Drews U 2007 Helper function of the Wolffian ducts and role of androgens in the development of the vagina. Sexual Development 1 100-110. (doi:10.1159/000100031)

Duncan PA, Shapiro LR, Stangel JJ, Klein RM \& Addonizio JC 1979 The MURCS association: Müllerian duct aplasia, renal aplasia, and cervicothoracic somite dysplasia. Journal of Pediatrics 95 399-402. (doi:10.1016/S0022-3476(79)80514-4)

Egarter C, Schurz B, Fitz R \& Grunberger W 1988 Hormonal situation in patients suffering from Mayer-Rokitanski-Kuster syndrome. Geburtshilfe und Frauenheilkunde 48 235-239. (doi:10.1055/s-2008-1026494)

Ekici AB, Strissel PL, Oppelt PG, Renner SP, Brucker S, Beckmann MW \& Strick R 2013 HOXA10 and HOXA13 sequence variations in human female genital malformations including congenital absence of the uterus and vagina. Gene 518 267-272. (doi:10.1016/j. gene.2013.01.030)

Erman Akar M, Ozekinci M, Alper O, Demir D, Cevikol C, Meric Bilekdemir A, Daloglu A, Ongut G, Senol Y, Ozdem S et al. 2015 Assessment of women who applied for the uterine transplant project as potential candidates for uterus transplantation. Journal of Obstetrics and Gynaecology Research 41 12-16. (doi:10.1111/jog.12486)

Fauser BC, Tarlatzis BC, Rebar RW, Legro RS, Balen AH, Lobo R, Carmina E, Chang J, Yildiz BO, Laven JS et al. 2012 Consensus on women's health aspects of polycystic ovary syndrome (PCOS): the Amsterdam ESHRE/ ASRM-Sponsored 3rd PCOS Consensus Workshop Group. Fertility and Sterility 97 28.e25-38.e25. (doi:10.1016/j.fertnstert.2011.09.024)

Fontana L, Gentilin B, Fedele L, Gervasini C \& Miozzo M 2016 Genetics of Mayer-Rokitansky-Küster-Hauser (MRKH) syndrome. Clinical Genetics 91 233-246. (doi:10.1111/cge.12883, Epub ahead of print)

Fraser IS, Baird DT, Hobson BM, Michie EA \& Hunter W 1973 Cyclical ovarian function in women with congenital absence of the uterus and vagina. Journal of Clinical Endocrinology and Metabolism 36 634-637. (doi:10.1210/jcem-36-4-634)

Gervasini C, Grati FR, Lalatta F, Tabano S, Gentilin B, Colapietro P, De Toffol S, Frontino G, Motta F, Maitz S et al. 2010 SHOX duplications found in some cases with type I Mayer-Rokitansky-Kuster-Hauser syndrome. Genetics in Medicine 12 634-640. (doi:10.1097/ GIM.0b013e3181ed6185)

Hall-Craggs MA, Williams CE, Pattison SH, Kirkham AP \& Creighton SM 2013 Mayer-Rokitansky-Kuster-Hauser syndrome: diagnosis with MR imaging. Radiology 269 787-792. (doi:10.1148/radiol.13130211)

Heikkilä M, Peltoketo H \& Vainio S 2001 Wnts and the female reproductive system. Journal of Experimental Zoology 290 616-623. (doi:10.1002/ jez.1112)
Ludwig KS 1998 The Mayer-Rokitansky-Küster syndrome. An analysis of its morphology and embryology. Part II: embryology. Archives of Gynecology and Obstetrics 262 27-42. (doi:10.1007/ s004040050225)

Melmed S, Casanueva FF, Hoffman AR, Kleinberg DL, Montori VM, Schlechte JA, Wass JA \& Endocrine Society 2011 Diagnosis and treatment of hyperprolactinemia: an Endocrine Society clinical practice guideline. Journal of Clinical Endocrinology and Metabolism 96 273-288. (doi:10.1210/jc.2010-1692)

Mueller A, Cupisti S, Binder H, Hoffmann I, Beckmann MW \& Dittrich R $2006 a$ The role of albumin in the calculation of free and bioavailable testosterone in women with hyperandrogenemia. In Vivo 20 403-408.

Mueller A, Dittrich R, Cupisti S, Beckmann MW \& Binder H 2006 b Is it necessary to measure free testosterone to assess hyperandrogenemia in women? The role of calculated free and bioavailable testosterone. Experimental and Clinical Endocrinology and Diabetes 114 182-187. (doi:10.1055/s-2006-924062)

Mueller A, Cupisti S, Binder H, Hoffmann I, Kiesewetter F, Beckmann MW \& Dittrich R 2007 Endocrinological markers for assessment of hyperandrogenemia in hirsute women. Hormone Research 67 35-41. (doi:10.1159/000096036)

Oppelt P, Renner SP, Brucker S, Strissel PL, Strick R, Oppelt PG, Doerr HG, Schott GE, Hucke J, Wallwiener D et al. 2005 The VCUAM (Vagina Cervix Uterus Adnex-associated Malformation) classification: a new classification for genital malformations. Fertility and Sterility $\mathbf{8 4}$ 1493-1497. (doi:10.1016/j.fertnstert.2005.05.036)

Oppelt P, Renner SP, Kellermann A, Brucker S, Hauser GA, Ludwig KS, Strissel PL, Strick R, Wallwiener D \& Beckmann MW 2006 Clinical aspects of Mayer-Rokitansky-Kuester-Hauser syndrome: recommendations for clinical diagnosis and staging. Human Reproduction 21 792-797. (doi:10.1093/humrep/dei381)

Philibert P, Biason-Lauber A, Rouzier R, Pienkowski C, Paris F, Konrad D, Schoenle E \& Sultan C 2008 Identification and functional analysis of a new WNT4 gene mutation among 28 adolescent girls with primary amenorrhea and müllerian duct abnormalities: a French collaborative study. Journal of Clinical Endocrinology and Metabolism 93 895-900. (doi:10.1210/jc.2007-2023)

Philibert P, Biason-Lauber A, Gueorguieva I, Stuckens C, Pienkowski C, Lebon-Labich B, Paris F \& Sultan C 2011 Molecular analysis of WNT4 gene in four adolescent girls with mullerian duct abnormality and hyperandrogenism (atypical Mayer-Rokitansky-Küster-Hauser syndrome). Fertility and Sterility 95 2683-2686. (doi:10.1016/j. fertnstert.2011.01.152)

O'Reilly MW, Taylor AE, Crabtree NJ, Hughes BA, Capper F, Crowley RK, Stewart PM, Tomlinson JW \& Arlt W 2014 Hyperandrogenemia predicts metabolic phenotype in polycystic ovary syndrome: the utility of serum androstenedione. Journal of Clinical Endocrinology and Metabolism 99 1027-1036. (doi:10.1210/jc.2013-3399)

Parr BA \& McMahon AP 1998 Sexually dimorphic development of the mammalian reproductive tract requires Wnt-7a. Nature 395 707-710. (doi:10.1038/27221)

Prunskaite-Hyyryläinen R, Shan J, Railo A, Heinonen KM, Miinalainen I, Yan W, Shen B, Perreault C \& Vainio SJ 2014 Wnt4, a pleiotropic signal for controlling cell polarity, basement membrane integrity, and antimüllerian hormone expression during oocyte maturation in the female follicle. FASEB Journal 28 1568-1581. (doi:10.1096/fj.13233247)

Rall K, Conzelmann G, Schäffeler N, Henes M, Wallwiener D, Möhrle M \& Brucker SY 2014 Acne and PCOS are less frequent in women with Mayer-Rokitansky-Küster-Hauser syndrome despite a high rate of hyperandrogenemia: a cross-sectional study. Reproductive Biology and Endocrinology 12 23. (doi:10.1186/1477-7827-12-23)

Rall K, Eisenbeis S, Henninger V, Henes M, Wallwiener D, Bonin M \& Brucker S 2015 Typical and atypical associated findings in a group of 346 patients with Mayer-Rokitansky-Kuester-Hauser Syndrome. Journal of Pediatric and Adolescent Gynecology 28 362-368. (doi:10.1016/j. jpag.2014.07.019)

Ravel C, Lorenço D, Dessolle L, Mandelbaum J, McElreavey K, Darai E \& Siffroi JP 2009 Mutational analysis of the WNT gene family in women with Mayer-Rokitansky-Kuster-Hauser syndrome. Fertility and Sterility $\mathbf{9 1}$ 1604-1607. (doi:10.1016/j.fertnstert.2008.12.006) 
Raziel A, Friedler S, Gidoni Y, Ben Ami I, Strassburger D \& Ron-El R 2012 Surrogate in vitro fertilization outcome in typical and atypical forms of Mayer-Rokitansky-Kuster-Hauser syndrome. Human Reproduction 27 126-130. (doi:10.1093/humrep/der356)

Strübbe EH, Willemsen WN, Lemmens JA, Thijn CJ \& Rolland R 1993 Mayer-Rokitansky-Küster-Hauser syndrome: distinction between two forms based on excretory urographic, sonographic, and laparoscopic findings. American Journal of Roentgenology $160331-334$. (doi:10.2214/ ajr.160.2.8424345)

Strissel PL, Oppelt P, Cupisti S, Stiegler E, Beckmann MW \& Strick R 2009 Assessment of pituitary and steroid hormones and members of the TGF-beta superfamily for ovarian function in patients with congenital uterus and vaginal aplasia (MRKH syndrome). Hormone and Metabolic Research 41 408-413. (doi:10.1055/s-0028-1105918)

Tai CC, Sala FG, Ford HR, Wang KS, Li C, Minoo P, Grikscheit TC \& Bellusci S 2009 Wnt5a knock-out mouse as a new model of anorectal malformation. Journal of Surgical Research 156 278-282. (doi:10.1016/j. jss.2009.03.087)

Tang R, Dang Y, Qin Y, Zou S, Li G, Wang Y \& Chen ZJ 2014 WNT9B in 542 Chinese women with Müllerian duct abnormalities: mutation analysis. Reproductive BioMedicine Online 28 503-507. (doi:10.1016/j. rbmo.2013.11.011)

Timmreck LS, Pan HA, Reindollar RH \& Gray MR 2003 WNT7A mutations in patients with Müllerian duct abnormalities. Journal of Pediatric and Adolescent Gynecology 16 217-221. (doi:10.1016/S10833188(03)00124-4)
Wang M, Li Y, Ma W, Li H, He F, Pu D, Su T \& Wang S 2014 Analysis of WNT9B mutations in Chinese women with Mayer-RokitanskyKüster-Hauser syndrome. Reproductive BioMedicine Online 28 80-85. (doi:10.1016/j.rbmo.2013.09.022)

Waschk DE, Tewes AC, Römer T, Hucke J, Kapczuk K, Schippert C, Hillemanns P, Wieacker P \& Ledig S 2016 Mutations in WNT9B are associated with Mayer-Rokitansky-Küster-Hauser syndrome. Clinical Genetics 89 590-596. (doi:10.1111/cge.12701)

Wathen NC, Perry L, Hodgkinson S \& Chard T 1985 The relationship between prolactin, dehydroepiandrosterone sulphate and testosterone in normally menstruating females. Acta Endocrinologica 109 173-175. (doi:10.1530/acta.0.1090173)

Yamaguchi TP, Bradley A, McMahon AP \& Jones S 1999 A Wnt5a pathway underlies outgrowth of multiple structures in the vertebrate embryo. Development 126 1211-1223.

Ylikorkala O \& Viinikka L 1979 Pituitary and ovarian function in women with congenitally absent uterus. Obstetrics and Gynecology $\mathbf{5 3}$ 137-139.

Received 27 July 2016

First decision 23 August 2016

Revised manuscript received 15 February 2017

Accepted 28 February 2017 